\title{
Effect on Insulin-Stimulated Release of D-Chiro-Inositol-Containing Inositolphosphoglycan Mediator during Weight Loss in Obese Women with and without Polycystic Ovary Syndrome
}

\author{
Kai I. Cheang, ${ }^{1,2}$ Sakita N. Sistrun, ${ }^{3}$ Kelley S. Morel, ${ }^{4}$ and John E. Nestler ${ }^{2,5}$ \\ ${ }^{1}$ Department of Pharmacotherapy \& Outcomes Science, School of Pharmacy, Virginia Commonwealth University, \\ P.O. Box 980533, Richmond, VA 23298-0533, USA \\ ${ }^{2}$ Virginia Commonwealth University Institute for Women's Health, P.O. Box 980319, Richmond, VA 23298-0319, USA \\ ${ }^{3}$ Bionutrition Service, Center for Clinical and Translational Research, Virginia Commonwealth University, \\ P.O. Box 980155, Richmond, VA 23298-0155, USA \\ ${ }^{4}$ Carilion Clinic Obstetrics \& Gynecology, 102 Highland Ave, Suite 455, Roanoke, VA 24013, USA \\ ${ }^{5}$ Division of Endocrinology and Metabolism, Department of Internal Medicine, School of Medicine, \\ Virginia Commonwealth University, P.O. Box 980111, Richmond, VA 23298-0111, USA
}

Correspondence should be addressed to Kai I. Cheang; kicheang@vcu.edu

Received 22 June 2016; Accepted 22 August 2016

Academic Editor: Franco Veglio

Copyright (C) 2016 Kai I. Cheang et al. This is an open access article distributed under the Creative Commons Attribution License, which permits unrestricted use, distribution, and reproduction in any medium, provided the original work is properly cited.

\begin{abstract}
Background. A deficiency of D-chiro-inositol-inositolphosphoglycan mediator (DCI-IPG) may contribute to insulin resistance in polycystic ovary syndrome (PCOS). Whether the relationship between impaired DCI-IPG release and insulin resistance is specific to PCOS rather than obesity is unknown. We assessed insulin-released DCI-IPG and its relationship to insulin sensitivity at baseline and after weight loss in obese women with and without PCOS. Methods. Obese PCOS $(n=16)$ and normal $(n=15)$ women underwent 8 weeks of a hypocaloric diet. The Matsuda index, area under the curve DCI-IPG (AUC DCI-IPG $_{\text {) }}$ AUC $_{\text {insulin }}$, and $\mathrm{AUC}_{\mathrm{DCI}-\mathrm{IPG}} / \mathrm{AUC}_{\text {insulin }}$ were measured during a $2 \mathrm{hr}$ OGTT at baseline and 8 weeks. Results. PCOS women had lower $\mathrm{AUC}_{\mathrm{DCI}-\mathrm{IPG}} / \mathrm{AUC}_{\text {insulin }}$ at baseline and a significant relationship between $\mathrm{AUC}_{\mathrm{DCI}-\mathrm{IPG}} / \mathrm{AUC}_{\text {insulin }}$ and Matsuda index $(p=0.0003)$, which was not present in controls. Weight loss was similar between PCOS $(-4.08 \mathrm{~kg})$ and normal women $(-4.29 \mathrm{~kg}, p=0.6281)$. Weight loss in PCOS women did not change the relationship between $\mathrm{AUC}_{\mathrm{DCI}-\mathrm{IPG}} / \mathrm{AUC}_{\mathrm{insulin}}$ and Matsuda index $(p=0.0100)$, and this relationship remained absent in control women. Conclusion. The association between $\mathrm{AUC}_{\mathrm{DCI}-\mathrm{IPG}} / \mathrm{AUC}_{\text {insulin }}$ and insulin sensitivity was only found in PCOS but not in normal women, and this relationship was unaffected by weight loss. DCI and its messenger may contribute to insulin resistance in PCOS independent of obesity.
\end{abstract}

\section{Introduction}

Polycystic ovary syndrome (PCOS) affects approximately $6-10 \%$ of women of reproductive age [1]. The disorder is characterized by chronic oligo- or anovulation and biochemical or clinical androgen excess. PCOS is also associated with increased risk for diabetes, metabolic syndrome, and early cardiovascular disease. Insulin resistance and its compensatory hyperinsulinemia play a central role in the pathogenesis of PCOS $[2,3]$. Multiple lines of evidence indicate that a putative inositolphosphoglycan (IPG) second messenger, D-chiro-inositol-inositolphosphoglycan mediator (DCIIPG), may mediate insulin action [4]. A deficiency of DCIIPG may contribute to insulin resistance in individuals with Type 2 diabetes [5] as well as women with PCOS [6,7]. Interventional studies with oral administration of DCI reported decreases in serum insulin and androgen levels, as well as improved ovulatory function in obese women with PCOS [8-10]. Conversely, administration of insulin sensitizers such as metformin [7] and pioglitazone [11] also increases 
insulin-stimulated release of DCI-IPG in women with PCOS.

Our group has previously demonstrated that the coupling between insulin action and release of DCI-IPG mediator is impaired in obese women with PCOS, as compared to nonobese normal women, suggesting that the insulin-stimulated release of bioactive DCI-IPG mediator is defective in PCOS women with obesity [12]. However, whether the relationship between impaired DCI-IPG mediator release and insulin resistance is specific to PCOS status or due to obesity per se is unknown. We hypothesize that the insulinstimulated DCI-IPG mediator modulates insulin sensitivity in women with PCOS but not in normal women, and a reduction in obesity does not affect this relationship. To test this hypothesis, we conducted a pilot weight loss intervention study in obese women with PCOS and obese normal women. We assessed the release of both insulin and DCI-IPG mediator during an oral glucose tolerance test (OGTT), as well as insulin sensitivity as measured by the Matsuda index, at baseline and after 8 weeks of a hypocaloric diet in obese women with and without PCOS.

\section{Materials and Methods}

2.1. Participants. This study was performed at the Clinical Research Service Unit of Virginia Commonwealth University's Center for Clinical and Translational Research. The study was approved by the Virginia Commonwealth University Institutional Review Board. All study participants provided informed consent.

Women in this study were obese $\left(\geq 30 \mathrm{~kg} / \mathrm{m}^{2}\right)$ and between the ages of 18 and 40 years. PCOS was defined by the modified Rotterdam criteria, after excluding other endocrine disorders [13]. In this study, all PCOS women had biochemical hyperandrogenemia and oligo- or amenorrhea (eight or few menstrual periods annually). Secondary causes of hyperandrogenemia or ovulatory dysfunction were excluded by normal thyroid function tests and serum prolactin and a fasting $17 \alpha$-hydroxyprogesterone $<200 \mathrm{ng} / \mathrm{dL}$. The control group consisted of regular cycling women with normal serum testosterone. The exclusion criteria for all women included weight loss attempts by either diet or exercise within 3 months of study participation, diabetes mellitus by fasting glucose or oral glucose tolerance test (OGTT), clinically significant pulmonary, cardiac, renal, hepatic, neurologic, psychiatric, infectious, neoplastic, and malignant disease, or pregnancy as documented by urine hCG. PCOS women with disorders associated with insulin resistance, for example, hypertension or dyslipidemia, were not excluded as long as they had been on a stable dose of medication for 6 months. Normal women were excluded if they had a history of gestational diabetes or had a first-degree relative with diabetes or if they demonstrated abnormal glucose tolerance at baseline or if they had hypertension or dyslipidemia.

2.2. Study Procedures. PCOS women were studied during the equivalent of the follicular phase of the cycle, and normal women were studied during the mid-follicular phase of the menstrual cycle (days 5-9), as documented by a serum progesterone $\leq 2 \mathrm{ng} / \mathrm{mL}$.

Because DCI may be ingested in a diet high in legumes or fruits, all subjects were interviewed by a dietician to identify those who may be consuming diets containing unusually high amounts of inositols. All participants were given instructions for a balanced mixed diet to be followed for at least three days prior to each study visit.

On the study day, the participants arrived at the Clinical Research Service Unit at Virginia Commonwealth University at 08:00 h after a 12-hour fast. Height and weight were measured to the nearest $0.1 \mathrm{~cm}$ and $0.1 \mathrm{~kg}$ using a precision stadiometer and digital scale. Waist was measured at the level of the umbilicus, and hip circumference was measured at the widest diameter of the buttocks to the nearest $0.1 \mathrm{~cm}$. Fasting blood samples were drawn at 08:15, 08:30, and 08:45 h and pooled for determination of fasting insulin, glucose, and sex steroids (testosterone). At 09:00 h, an OGTT was performed by administering $75 \mathrm{~g}$ oral glucose. Blood samples for plasma glucose, insulin, and DCI-IPG were collected every 15 minutes for 2 hours.

After glucose and DCI assessments, the participants met with a study dietician for instruction on a hypocaloric diet. A diet-overview handout, instructional nutrition labels, sample menus and recipes, and a book on counting calories were provided. The women were instructed to follow an 8 -week course of standardized hypocaloric diet containing $50 \%$ carbohydrates, $30 \%$ total lipids, and $20 \%$ proteins. They were instructed to maintain these hypocaloric diets by caloric restriction to create a deficit of $500-1000 \mathrm{kcal} / \mathrm{day}$, as per obesity management guidelines of the National Heart, Lung, and Blood Institute [14]. This hypocaloric diet has been shown to yield weight loss of about 1 to $2 \mathrm{lbs} /$ week [14]. The women were instructed specifically to avoid making any conscious effort to modify physical activity or attempt other weight loss methods in addition to the hypocaloric diets per this protocol. This is because physical activity improves insulin sensitivity even in the absence of substantial weight loss [15] and will confound our investigation of the effect of weight reduction in DCI handling and insulin sensitivity in these women. During this 8-week period, the participants purchased and prepared their own meals and maintained daily food logs. They attended follow-up visits once weekly for weight measurements. During these weekly visits, they submitted their food logs and received follow-up consultations with the study dietician.

The women returned for DCI and insulin sensitivity measurements after 8 weeks of dietary intervention. After confirmation that they were in the equivalent of the follicular phase of the menstrual cycle by serum progesterone, all measurements and testing performed at baseline (anthropometric measurements, OGTT, and blood sampling) were repeated.

2.3. Laboratory Analyses. Serum and plasma were stored at $-80^{\circ} \mathrm{C}$ until being assayed. Serum glucose was measured by glucose oxidative method (YSI 2300 Stat Plus Glucose Analyzer; Yellow Springs Instruments). Serum insulin levels were measured by enzyme-linked immunosorbent assay (ELISA) 
(Alpco Diagnostics, Salem NH). Serum testosterone and sex hormone binding globulin (SHBG) were measured via ELISA (Alpco Diagnostics). Free testosterone was calculated using the method of Södergard et al. [16]. DCI-IPG bioactivity was measured using an in-house bioactivity assay developed by the laboratory of JEN, as previously described [7].

2.4. Statistical Analysis. We examined the response of serum insulin concentrations and the relative bioactivity of DCIIPG to the oral administration of glucose by calculating the areas under the respective response curves (AUC) by the trapezoidal rule. Since insulin is thought to mediate the release of DCI-IPG after a glucose load [17] and there are interparticipant variations in $\mathrm{AUC}_{\text {insulin, }}$, the ratio of $\mathrm{AUC}_{\mathrm{DCI}-\mathrm{IPG}} / \mathrm{AUC}_{\text {insulin }}$ more accurately reflects insulinmediated release of DCI-IPG than $\mathrm{AUC}_{\text {DCI-IPG }}$ alone. Hence, we used this ratio in our analyses. Whole body insulin sensitivity as described by Matsuda and DeFronzo [18] was used to assess insulin sensitivity.

Comparisons between groups at baseline were made with Student's two-tailed $t$-test. To assess within group effects from baseline to after treatment, a matched pairs two-tailed $t$ test was performed. To assess the treatment effects between groups, the changes in each variable (after weight loss minus baseline) were compared using a two-tailed $t$-test. Pearson's correlation was used to assess the association between change in Matsuda index and change in bioactive DCI-IPG released per unit of insulin during OGTT, after linearity and normality of residuals were assessed.

Distribution of the data was assessed by normal quantile plots. Variables not in normal distribution were logtransformed for analyses and then backtransformed into their original units for reporting. Data were presented as mean \pm standard deviation or geometric mean (95\% confidence interval $[\mathrm{CI}])$ for parameters that were transformed for analyses. $p<0.05$ was considered statistically significant. Analyses were performed by JMP 12.0 (SAS Institute, NC).

\section{Results}

A total of 80 women provided consent to participate. Of these, 19 met exclusion criteria before study entry. Of the remaining 34 PCOS and 27 normal women, 18 PCOS and 12 normal women dropped out prior to the follow-up visit. Hence, 16 PCOS and 15 normal women completed the study. The attrition rate in this study was similar to that of other dietary-based weight loss studies [19]. Because the purpose of this study is to evaluate the relationship between changes in DCI-IPG mediator release and changes in insulin sensitivity during weight loss in PCOS as compared to normal women, we only included women who completed the study.

3.1. Baseline Characteristics. At baseline, control women and women with PCOS did not differ in terms of age, racial mix, BMI, or waist-to-hip ratio (Table 1). As expected, PCOS women tended to have significantly higher serum total testosterone. Although women with PCOS had higher $\mathrm{AUC}_{\text {glucose }}$ and $\mathrm{AUC}_{\text {insulin }}$ and lower whole body insulin sensitivity as
TABLE 1: Baseline characteristics and serum hormone concentrations.

\begin{tabular}{|c|c|c|c|}
\hline Parameter & $\operatorname{PCOS}(n=16)$ & Control $(n=15)$ & $p$ value \\
\hline Age (years) & $26.9(4.6)$ & $27.5(5.7)$ & 0.7267 \\
\hline Race & & & 0.5649 \\
\hline African-American & 7 & 7 & \\
\hline Caucasian & 8 & 7 & \\
\hline Other & 1 & 1 & \\
\hline Weight $(\mathrm{kg})$ & $99.2(13.3)$ & $97.6(15.4)$ & 0.7508 \\
\hline BMI $\left(\mathrm{kg} / \mathrm{m}^{2}\right)$ & $36.6(5.1)$ & $35.8(4.8)$ & 0.6507 \\
\hline $\begin{array}{l}\text { Waist circumference } \\
(\mathrm{cm})\end{array}$ & $101.6(12.7)$ & $99.9(9.9)$ & 0.6860 \\
\hline Waist/hip ratio & $0.82(0.05)$ & $0.80(0.08)$ & 0.4102 \\
\hline $\begin{array}{l}\text { Total testosterone } \\
\text { (ng/dL) }\end{array}$ & $63.1(34.4)$ & $27.7(8.0)$ & 0.0006 \\
\hline $\begin{array}{l}\text { Free testosterone } \\
(\mathrm{ng} / \mathrm{dL})\end{array}$ & $0.90(0.87)$ & $0.44(0.25)$ & 0.0786 \\
\hline $\begin{array}{l}\text { Fasting insulin } \\
(\mathrm{mg} / \mathrm{dL})^{*}\end{array}$ & $7.58(5.65-10.15)$ & $8.12(5.06-13.03)$ & 0.7897 \\
\hline $\begin{array}{l}\text { Fasting glucose } \\
(\mathrm{mg} / \mathrm{dL})\end{array}$ & $85.5(8.1)$ & $84.2(3.8)$ & 0.6000 \\
\hline $\begin{array}{l}\text { AUC insulin } \\
(\mathrm{min} \cdot \mathrm{mg} / \mathrm{dL})\end{array}$ & 7999 (5058) & $5667(2890)$ & 0.1323 \\
\hline $\begin{array}{l}\text { AUC glucose } \\
(\mathrm{min} \cdot \mathrm{mg} / \mathrm{dL})\end{array}$ & $14781(3016)$ & $12963(2245)$ & 0.0715 \\
\hline Matsuda index & $5.22(2.18)$ & $6.94(4.06)$ & 0.1577 \\
\hline $\begin{array}{l}\text { AUC DCI-IPG } \\
(\% \min )\end{array}$ & $15279(6030)$ & 21441 (19376) & 0.2539 \\
\hline $\begin{array}{l}\text { Ratio of AUC } \\
\text { DCI-IPG/AUC } \\
\text { insulin }(\% / \mu \mathrm{IU} / \mathrm{mL})^{*}\end{array}$ & $2.76(1.79-3.73)$ & $4.83(2.37-7.29)$ & 0.0377 \\
\hline
\end{tabular}

Values are mean (SD) or geometric mean (95\% confidence interval) when indicated by $*$.

determined by Matsuda index, these differences did not attain statistical significance.

At baseline, women with PCOS had significantly lower $\mathrm{AUC}_{\mathrm{DCI}-\mathrm{IPG}} / \mathrm{AUC}_{\text {insulin }}$ ratios. In PCOS women, there was a significant relationship between $\mathrm{AUC}_{\mathrm{DCI}-\mathrm{IPG}} / \mathrm{AUC}_{\text {insulin }}$ and Matsuda index $(r=0.8065, p=0.0003$, Figure 1(a)). This relationship was not found in control women $(r=0.1488$, $p=0.6445$, Figure $1(\mathrm{~b}))$.

3.2. Changes in Insulin, Glucose, and the Bioactivity Profiles of DCI-IPG after Weight Loss. After the weight loss intervention, both PCOS $(-4.08 \pm 3.65 \mathrm{~kg}, p=0.0013)$ and control women $(-4.69 \pm 2.98 \mathrm{~kg}, p=0.0005)$ lost weight compared to baseline. The amount of weight loss did not differ between the groups ( $p=0.6281$ ) (Table 2). However, the Matsuda index improved significantly only in normal women (from $6.94 \pm 4.06$ to $9.53 \pm 4.79, p=0.0479$ ) but not in PCOS women (from $5.22 \pm 2.18$ to $5.39 \pm 2.52, p=0.8209$ ). Weight loss did not significantly increase $\mathrm{AUC}_{\mathrm{DCI}-\mathrm{IPG}} / \mathrm{AUC}_{\text {insulin }}$ from baseline in either group $(p=0.6387$ in PCOS and $p=$ 0.9697 in normal women). 


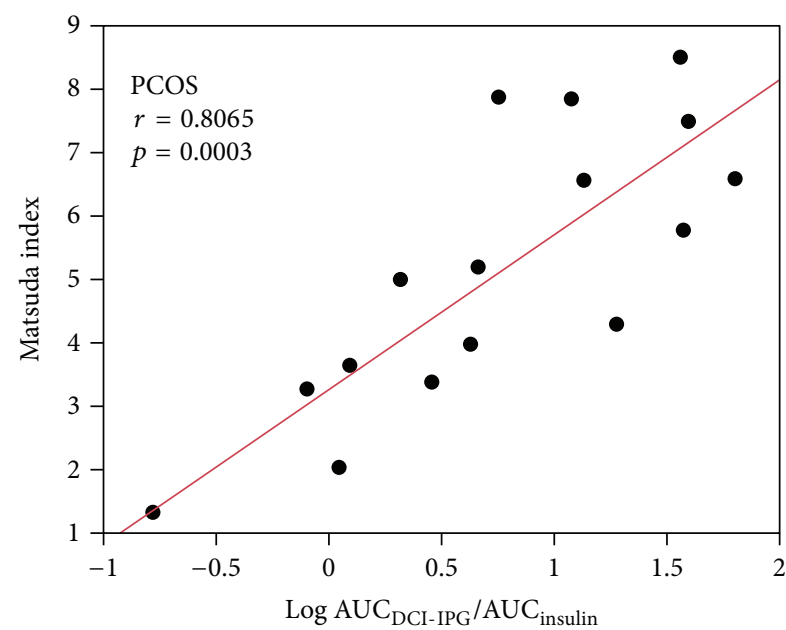

(a)

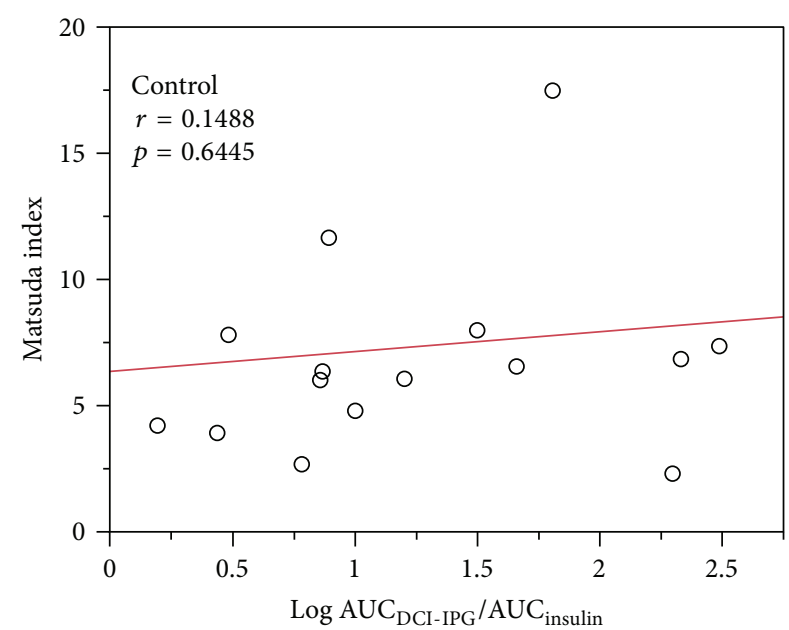

(b)

FIGURE 1: Relationship between baseline Matsuda index and release of the bioactive DCI-IPG messenger per unit of insulin released during $\operatorname{OGTT}$ in PCOS (•, a) and normal (O, b) women. DCI-IPG, D-chiro-inositol-inositolphosphoglycan mediator.

TABLE 2: Changes in metabolic parameters after 8 weeks of weight loss intervention in women with and without PCOS.

\begin{tabular}{lccc}
\hline Parameter & PCOS $(n=16)$ & Control $(n=15)$ & $p$ value \\
\hline Weight $(\mathrm{kg})$ & $-4.08(-2.13$, & $-4.69(-2.89$, & 0.6281 \\
& $-6.02)^{\mathrm{a}}$ & $-6.49)^{\mathrm{a}}$ & \\
& $-1.46(-0.72$, & $-1.80(-1.14$, & 0.4829 \\
BMI $\left(\mathrm{kg} / \mathrm{m}^{2}\right)$ & $-2.20)^{\mathrm{a}}$ & $-2.45)^{\mathrm{a}}$ & \\
& $-0.014(-0.034$, & $-0.040(-0.107$, & 0.3878 \\
Waist/hip ratio & $0.006)$ & $0.027)$ & \\
& & $-5.0(-10.6$, & 0.0625 \\
Fasting insulin & $+1.8(-2.2,+5.7)$ & $+0.6)$ \\
(mg/dL) & & $+0.21(-2.35$, & 0.5041 \\
Fasting glucose & $-1.15(-4.43$, & $+2.77)$ \\
(mg/dL) & $+2.13)$ & $-1403(-2886$, & 0.1961 \\
AUC insulin & $-1009(-2601$, & $-80)^{\mathrm{b}}$ & \\
(min·mg/dL) & $+642)$ & $+152.8(-1245$, & 0.1600 \\
AUC glucose & $-961(-1944$, & $+1550)$ & \\
(min·mg/dL) & $+21)$ & $+2.60(+0.38$, & 0.1168 \\
Matsuda index & $+0.17(-0.87$, & $+5.58)^{\mathrm{c}}$ & \\
& $+1.21)$ & $-3754(-11496$, & 0.6765 \\
AUC DCI-IPG & $-446(-4078$, & $+3989)$ & \\
(\% min) & $+3185)$ & & \\
Ratio of AUC & $+1.085(-0.709$, & $+1.049(-0.798$, & 0.8805 \\
DCI-IPG/AUC & $1.663)$ & $1.380)$ & \\
insulin $(\% / \mu \mathrm{IU} / \mathrm{mL})$ & & & \\
\hline
\end{tabular}

Data are expressed as mean (95\% confidence interval).

${ }^{a} p<0.002$ for within group difference between baseline and after weight loss.

${ }_{\mathrm{b}} p=0.0134$ for within group difference between baseline and after weight loss.

${ }^{c} p=0.0479$ for within group difference between baseline and after weight loss.

3.3. Relationship between DCI-IPG Mediator Bioactivity and Insulin Sensitivity after Weight Loss. Weight loss did not change the relationship between $\mathrm{AUC}_{\mathrm{DCI}-\mathrm{IPG}} / \mathrm{AUC}_{\text {insulin }}$ and Matsuda index in PCOS women. Among women with PCOS, after weight loss there remained a significant relationship between change in $\mathrm{AUC}_{\mathrm{DCI}-\mathrm{IPG}} / \mathrm{AUC}_{\text {insulin }}$ and change in Matsuda index $(r=0.6412, p=0.0100$, Figure 2(a)). This relationship was not found in control women $(r=0.2717, p=$ 0.3928 , Figure 2(b)).

\section{Discussion}

In this study, we observed that obese women with PCOS, as compared to normal women with similar BMI, have decreased insulin-released DCI-IPG mediator during an OGTT. We observed that the relationship between insulin sensitivity as measured by the Matsuda index and $\mathrm{AUC}_{\mathrm{DCI}-\mathrm{IPG}} / \mathrm{AUC}_{\text {insulin }}$ was found only in obese women with PCOS and not in obese normal women. Furthermore, this relationship was unaffected by weight loss. After a similar amount of weight loss, a significant relationship between $\mathrm{AUC}_{\mathrm{DCI}-\mathrm{IPG}} / \mathrm{AUC}_{\text {insulin }}$ and Matsuda index remained only in women with PCOS but was not present in normal women.

The findings of our study are in concordance with our previous report of significantly lower $\mathrm{AUC}_{\mathrm{DCI}-\mathrm{IPG}} / \mathrm{AUC}_{\text {insulin }}$ ratios in PCOS women as compared to normal women [6]. However, in the previous study, PCOS participants had a significantly higher BMI $\left(33.9 \mathrm{~kg} / \mathrm{m}^{2}\right)$ than normal women $\left(25.6 \mathrm{~kg} / \mathrm{m}^{2}, p=0.002\right)$. Our current study demonstrates that, even with similar obesity, $\mathrm{AUC}_{\mathrm{DCI}-\mathrm{IPG}} / \mathrm{AUC}_{\text {insulin }}$ remained lower in PCOS women compared to normal women ( $p=0.0377$, Table 1$)$. Our findings suggest that bioactivity of the DCI-IPG mediator is decreased in PCOS independent of obesity.

We also observed that the relationship between insulin sensitivity and $\mathrm{AUC}_{\mathrm{DCI}-\mathrm{IPG}} / \mathrm{AUC}_{\text {insulin }}$ was present only in women with PCOS (Figure 1(a)) and not in normal women (Figure 1(b)) and that this finding remained evident after weight loss (Figures 2(a) and 2(b)). These results are supported by our previous findings of a significant association 


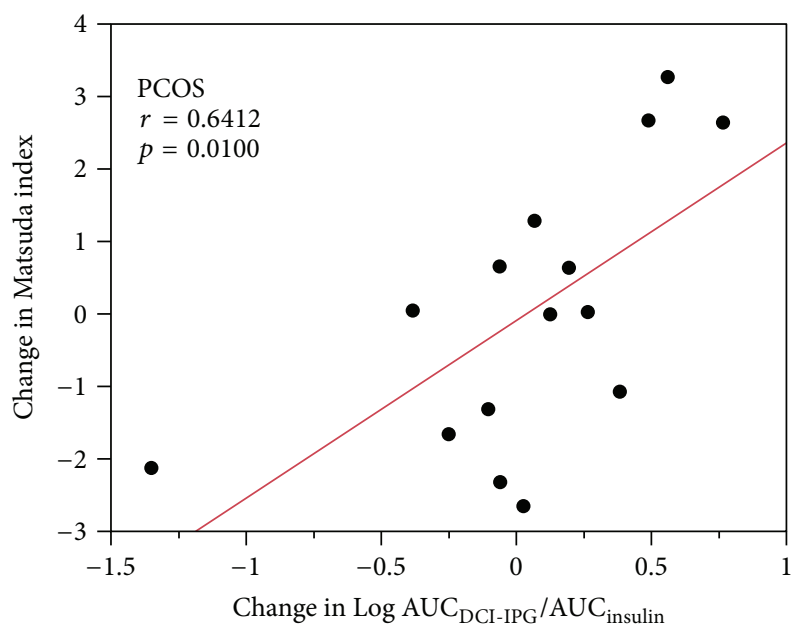

(a)

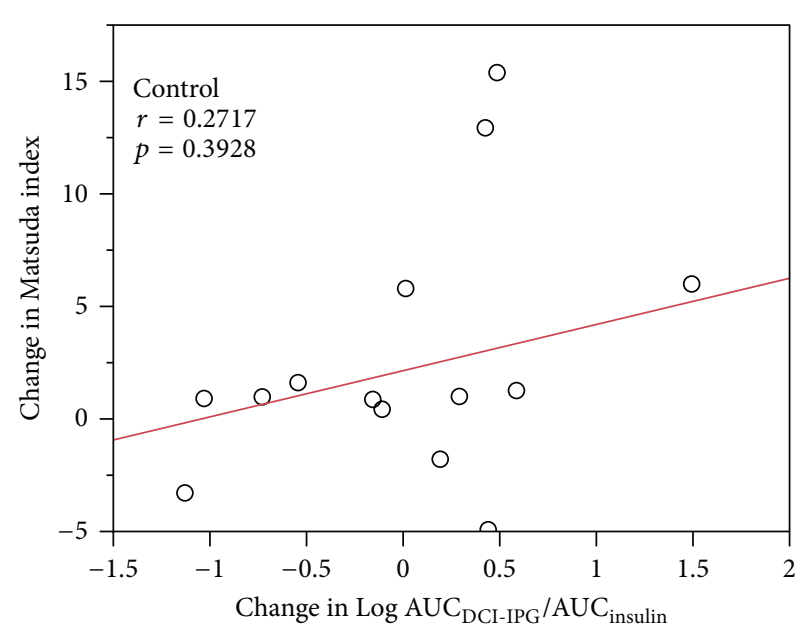

(b)

FIGURE 2: Relationship between change in Matsuda index and change in release of the bioactive DCI-IPG messenger per unit of insulin released during OGTT in PCOS $(\bullet, a)$ and normal $(\mathrm{O}, \mathrm{b})$ women after 8 weeks of weight loss intervention. DCI-IPG, D-chiro-inositolinositolphosphoglycan mediator.

between change in insulin sensitivity and change in DCIIPG released per unit of insulin with oral DCI administration in PCOS women [20]. However, previous studies only examined this association in women with PCOS, and whether $\mathrm{AUC}_{\mathrm{DCI}-\mathrm{IPG}} / \mathrm{AUC}_{\text {insulin }}$ is correlated with insulin sensitivity in normal women with similar BMI has been unknown. To the authors' knowledge, this is the first report suggesting that DCI-IPG mediator release may not play a major role in insulin sensitivity in normal obese women.

Weight loss did not affect the relationship between insulin sensitivity and $\mathrm{AUC}_{\mathrm{DCI}-\mathrm{IPG}} / \mathrm{AUC}_{\text {insulin }}$ in obese women with PCOS in this study. This finding is in line with our previous reports supporting that DCI deficiency in PCOS may be unrelated to adiposity. To wit, administration of oral DCI improved $\mathrm{AUC}_{\text {insulin }}$, serum androgens, and ovulation to both obese [8] and lean [9] women with PCOS.

In this current study, weight loss did not significantly improve $\mathrm{AUC}_{\mathrm{DCI}-\mathrm{IPG}} / \mathrm{AUC}_{\text {insulin }}$ in either PCOS or normal women. In contrast, previous studies demonstrated that insulin sensitizers such as metformin [7] and rosiglitazone [11] improved the availability of DCI-IPG mediator release in women with PCOS.

Why do insulin sensitizers, but not weight loss as described in this study, improve the $\mathrm{AUC}_{\mathrm{DCI}-\mathrm{IPG}} / \mathrm{AUC}_{\text {insulin }}$ bioactivity profile in women with PCOS? One reason could be that weight loss of more than $4 \mathrm{~kg}$ in this study did not improve insulin sensitivity in obese women with PCOS. At first glance, our results seem to contradict previous research supporting the role of weight loss in improving insulin sensitivity in PCOS [21]. However, there is tremendous heterogeneity in the effect of weight loss on improving insulin sensitivity and other features of PCOS $[22,23]$. In one weight loss study, as many as $50 \%$ of PCOS women did not have improved insulin sensitivity as measured by HOMA and, commensurably, no improvement in menstrual cyclicity, despite similar fat losses in both responders and nonresponders [23].

We did not observe a difference in the amount of weight loss between women with and without PCOS in this study. There have been conflicting reports about the role of insulin resistance in the regulation of obesity. Some studies suggested insulin resistance predicted weight gain [24], more weight loss [25], or no effect on weight loss [26] in obese individuals. Hence, the knowledge that weight loss is not different between PCOS and normal women when given the same hypocaloric diet can be reassuring to women with PCOS who are attempting weight loss.

A strength of this study includes similar BMI between PCOS and normal women, which helped elucidate that the relationship between $\mathrm{AUC}_{\mathrm{DCI}-\mathrm{IPG}} / \mathrm{AUC}_{\text {insulin }}$ bioactivity and insulin sensitivity is specific to PCOS and not obesity. These results are novel since the roles of DCI-IPG mediator in normal obese women have not been previously explored.

A weakness of the study is that the amount of weight loss achieved in both groups of women may have been inadequate to illicit changes in DCI-IPG/insulin ratio. Although the amount of weight loss ( $0.5 \mathrm{~kg}$ or approximately $1 \mathrm{lb}$ per week) was in accordance with current weight management guidelines [14], over the course of the 8-week study period, it resulted in a reduction in weight by about $4 \mathrm{~kg}$ in both groups, which was less than that achieved in other weight loss studies in PCOS [23, 27]. A study with a longer duration would have resulted in a bigger magnitude in weight reduction.

In conclusion, this study demonstrated that obese women with PCOS, as compared to normal women with similar BMI, have decreased insulin-released DCI-IPG mediator during OGTT. The relationship between insulin sensitivity and $\mathrm{AUC}_{\mathrm{DCI}-\mathrm{IPG}} / \mathrm{AUC}_{\text {insulin }}$ is only found in women with PCOS but not in normal women. Furthermore, this relationship is unaffected by weight loss. After a similar amount of 
weight loss, a significant relationship between $\mathrm{AUC}_{\mathrm{DCI}-\mathrm{IPG}} /$ $\mathrm{AUC}_{\text {insulin }}$ and Matsuda index is only found in women with PCOS but not in normal women. Combined with previous studies of oral DCI administration in PCOS women by our group and others, this study reinforces the contribution of DCI and its messenger in its role in insulin resistance in women with PCOS independent of obesity.

\section{Competing Interests}

The authors declare that they have no competing interests.

\section{Acknowledgments}

The authors would like to thank Dr. Jamal T. Aldajaei for his invaluable assistance in laboratory analyses for the study. This work was supported by National Institutes of Health Grant K23 K23HD049454 (to Kai I. Cheang) and in part by CTSA Award no. ULTR000058 from the National Center for Advancing Translational Sciences.

\section{References}

[1] E. S. Knochenhauer, T. J. Key, M. Kahsar-Miller, W. Waggoner, L. R. Boots, and R. Azziz, "Prevalence of the polycystic ovary syndrome in unselected black and white women of the southeastern United States: a prospective study," The Journal of Clinical Endocrinology \& Metabolism, vol. 83, no. 9, pp. 30783082, 1998.

[2] J. E. Nestler, D. J. Jakubowicz, A. F. de Vargas, C. Brik, N. Quintero, and F. Medina, "Insulin stimulates testosterone biosynthesis by human thecal cells from women with polycystic ovary syndrome by activating its own receptor and using inositolglycan mediators as the signal transduction system," The Journal of Clinical Endocrinology \& Metabolism, vol. 83, no. 6, pp. 2001-2005, 1998.

[3] A. Dunaif, J. Mandeli, H. Fluhr, and A. Dobrjansky, "The impact of obesity and chronic hyperinsulinemia on gonadotropin release and gonadal steroid secretion in the polycystic ovary syndrome," Obstetrical and Gynecological Survey, vol. 43, no. 11, pp. 688-690, 1988.

[4] G. Romero and J. Larner, "Insulin mediators and the mechanism of insulin action," Advances in Pharmacology, vol. 24, pp. 21-50, 1993.

[5] I. Asplin, G. Galasko, and J. Larner, "Chiro-inositol deficiency and insulin resistance: a comparison of the chiro-inositol- and the myo-inositol-containing insulin mediators isolated from urine, hemodialysate, and muscle of control and type II diabetic subjects," Proceedings of the National Academy of Sciences of the United States of America, vol. 90, no. 13, pp. 5924-5928, 1993.

[6] J.-P. Baillargeon, E. Diamanti-Kandarakis, R. E. Ostlund Jr., T. Apridonidze, M. J. Iuorno, and J. E. Nestler, "Altered D-chiroinositol urinary clearance in women with polycystic ovary syndrome," Diabetes Care, vol. 29, no. 2, pp. 300-305, 2006.

[7] J.-P. Baillargeon, M. J. Iuorno, D. J. Jakubowicz, T. Apridonidze, N. He, and J. E. Nestler, "Metformin therapy increases insulinstimulated release of D-chiro-inositol-containing inositolphosphoglycan mediator in women with polycystic ovary syndrome," The Journal of Clinical Endocrinology \& Metabolism, vol. 89, no. 1, pp. 242-249, 2004.
[8] J. E. Nestler, D. J. Jakubowicz, P. Reamer, R. D. Gunn, and G. Allan, "Ovulatory and metabolic effects of D-chiro-inositol in the polycystic ovary syndrome," The New England Journal of Medicine, vol. 340, no. 17, pp. 1314-1320, 1999.

[9] M. J. Iuorno, D. J. Jakubowicz, J.-P. Baillargeon et al., "Effects of d-chiro-inositol in lean women with the polycystic ovary syndrome," Endocrine Practice, vol. 8, no. 6, pp. 417-423, 2002.

[10] A. S. Laganà, L. Barbaro, and A. Pizzo, "Evaluation of ovarian function and metabolic factors in women affected by polycystic ovary syndrome after treatment with d-Chiro-Inositol," Archives of Gynecology and Obstetrics, vol. 291, no. 5, pp. 11811186, 2015.

[11] A. Gupta, D. Jakubowicz, and J. E. Nestler, "Pioglitazone therapy increases insulin-stimulated release of d-chiro-inositolcontaining inositolphosphoglycan mediator in women with polycystic ovary syndrome," Metabolic Syndrome and Related Disorders, 2016.

[12] J.-P. Baillargeon, M. J. Iuorno, T. Apridonidze, and J. E. Nestler, "Uncoupling between insulin and release of a D-chiro-inositolcontaining inositolphosphoglycan mediator of insulin action in obese women with polycystic ovary syndrome," Metabolic Syndrome and Related Disorders, vol. 8, no. 2, pp. 127-136, 2010.

[13] R. Azziz, E. Carmina, D. Dewailly et al., "Position statement: criteria for defining polycystic ovary syndrome as a predominantly hyperandrogenic syndrome: an androgen excess society guideline," Journal of Clinical Endocrinology and Metabolism, vol. 91, no. 11, pp. 4237-4245, 2006.

[14] The Obesity Society, "Guidelines for management of the obese and overweight," Obesity, vol. 6, no. 2, pp. 51S-179S, 1998.

[15] N. G. Boulé, S. J. Weisnagel, T. A. Lakka et al., "Effects of exercise training on glucose homeostasis," Diabetes Care, vol. 28, no. 1, pp. 108-114, 2005.

[16] R. Södergard, T. Bäckström, V. Shanbhag, and H. Carstensen, "Calculation of free and bound fractions of testosterone and estradiol-17 $\beta$ to human plasma proteins at body temperature," Journal of Steroid Biochemistry, vol. 16, no. 6, pp. 801-810, 1982.

[17] P. N. Shashkin, E. F. Shashkina, E. Fernqvist-Forbes, Y.-P. Zhou, V. Grill, and A. Katz, "Insulin mediators in man: effects of glucose ingestion and insulin resistance," Diabetologia, vol. 40, no. 5, pp. 557-563, 1997.

[18] M. Matsuda and R. A. DeFronzo, "Insulin sensitivity indices obtained from oral glucose tolerance testing: comparison with the euglycemic insulin clamp," Diabetes Care, vol. 22, no. 9, pp. $1462-1470,1999$.

[19] M. L. Dansinger, J. A. Gleason, J. L. Griffith, H. P. Selker, and E. J. Schaefer, "Comparison of the atkins, ornish, weight watchers, and zone diets for weight loss and heart disease risk reduction: a randomized trial," The Journal of the American Medical Association, vol. 293, no. 1, pp. 43-53, 2005.

[20] K. I. Cheang, J.-P. Baillargeon, P. A. Essah et al., "Insulinstimulated release of d-chiro-inositol-containing inositolphosphoglycan mediator correlates with insulin sensitivity in women with polycystic ovary syndrome," Metabolism: Clinical and Experimental, vol. 57, no. 10, pp. 1390-1397, 2008.

[21] L. J. Moran, S. K. Hutchison, R. J. Norman, and H. J. Teede, "Lifestyle changes in women with polycystic ovary syndrome," Cochrane Database of Systematic Reviews, no. 2, Article ID CD007506, 2011.

[22] R. Pasquali, A. Gambineri, C. Cavazza et al., "Heterogeneity in the responsiveness to long-term lifestyle intervention and predictability in obese women with polycystic ovary syndrome," 
European Journal of Endocrinology, vol. 164, no. 1, pp. 53-60, 2011.

[23] L. J. Moran, M. Noakes, P. M. Clifton, L. Tomlinson, and R. J. Norman, "Dietary composition in restoring reproductive and metabolic physiology in overweight women with polycystic ovary syndrome," The Journal of Clinical Endocrinology \& Metabolism, vol. 88, no. 2, pp. 812-819, 2003.

[24] R. J. Sigal, M. El-Hashimy, B. C. Martin, J. S. Soeldner, A. S. Krolewski, and J. H. Warram, "Acute postchallenge hyperinsulinemia predicts weight gain: a prospective study," Diabetes, vol. 46, no. 6, pp. 1025-1029, 1997.

[25] P. Evangelou, T. Tzotzas, G. Christou, M. S. Elisaf, and D. N. Kiortsis, "Does the presence of metabolic syndome influence weight loss in obese and overweight women?" Metabolic Syndrome and Related Disorders, vol. 8, no. 2, pp. 173-178, 2010.

[26] T. McLaughlin, F. Abbasi, M. Carantoni, P. Schaaf, and G. Reaven, "Differences in insulin resistance do not predict weight loss in response to hypocaloric diets in healthy obese women," Journal of Clinical Endocrinology and Metabolism, vol. 84, no. 2, pp. 578-581, 1999.

[27] K. M. Hoeger, L. Kochman, N. Wixom, K. Craig, R. K. Miller, and D. S. Guzick, "A randomized, 48-week, placebo-controlled trial of intensive lifestyle modification and/or metformin therapy in overweight women with polycystic ovary syndrome: a pilot study," Fertility and Sterility, vol. 82, no. 2, pp. 421-429, 2004. 


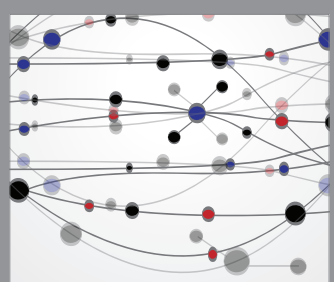

The Scientific World Journal
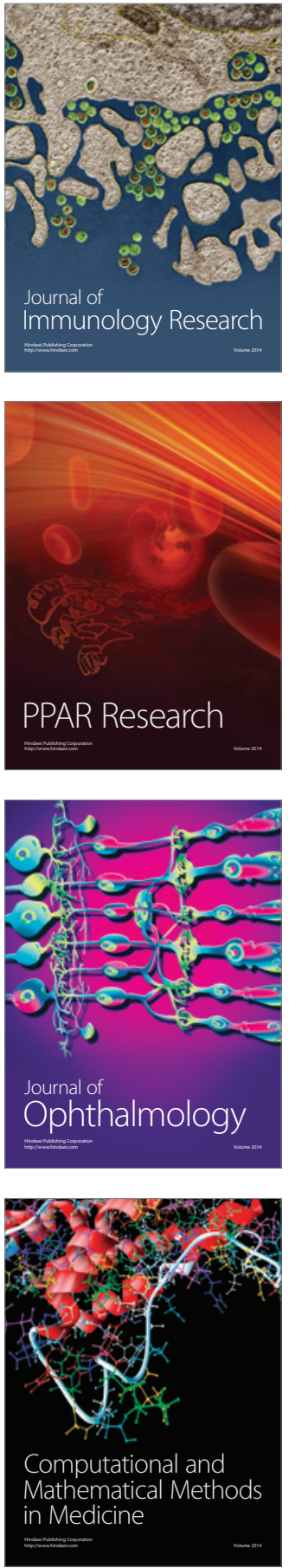

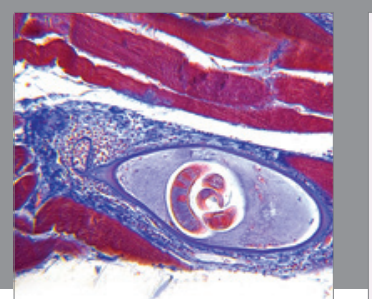

Gastroenterology Research and Practice

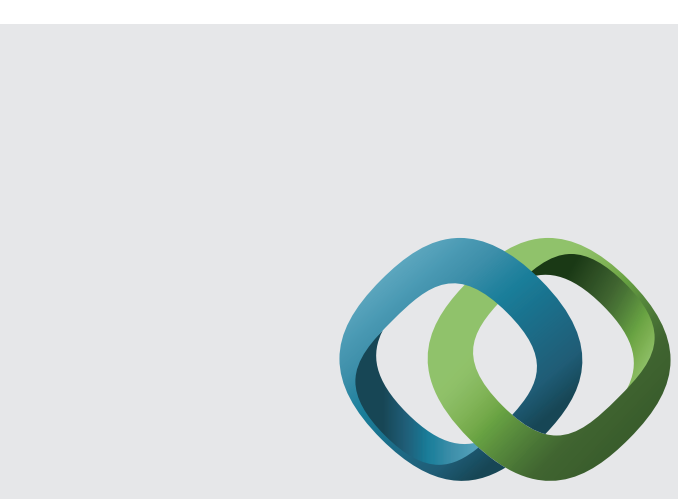

\section{Hindawi}

Submit your manuscripts at

http://www.hindawi.com
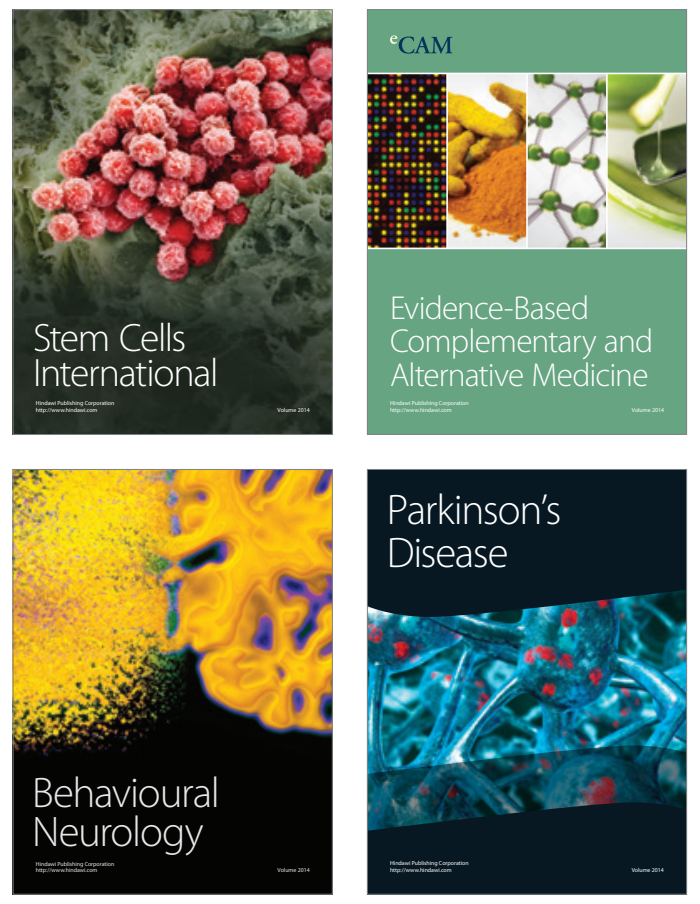
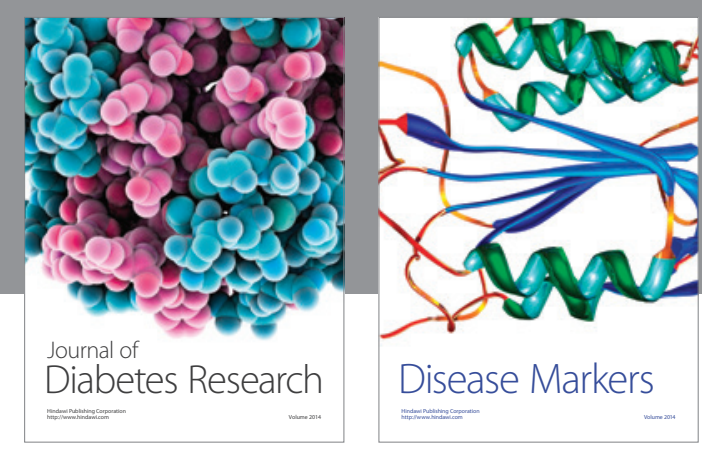

Disease Markers
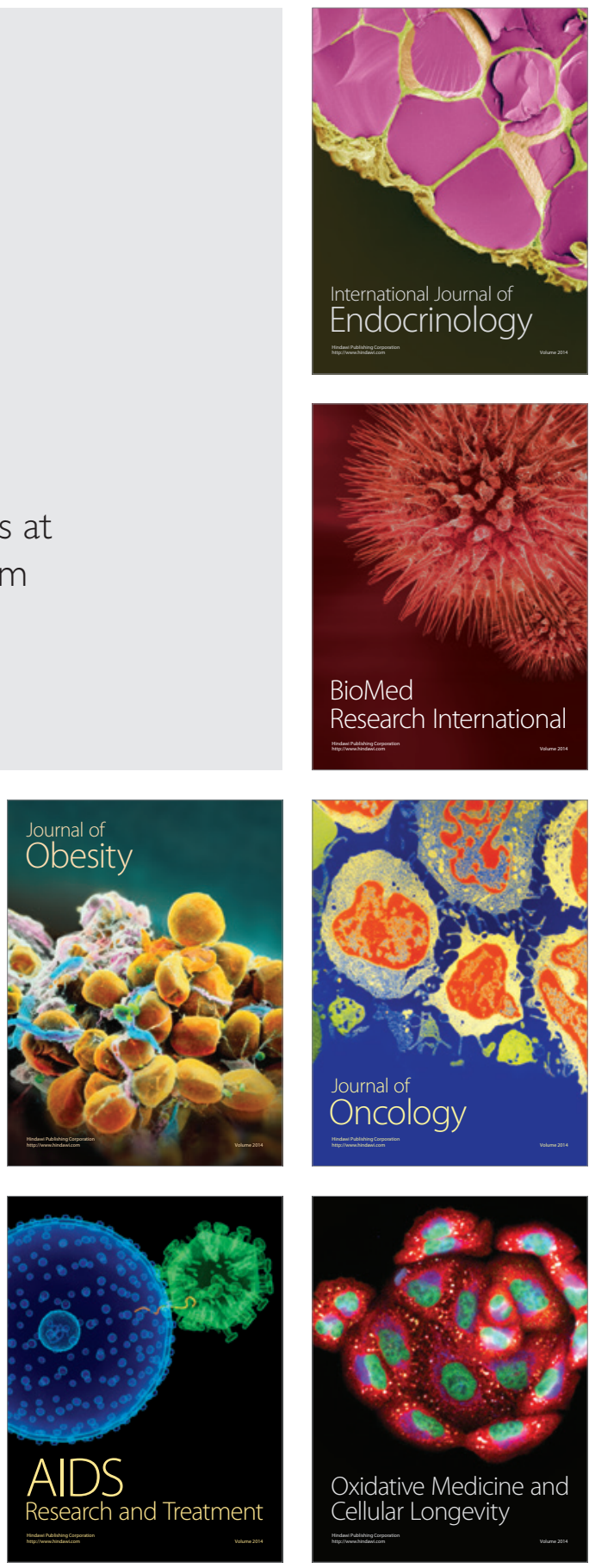